Article

\title{
Fabrications of Hetero-Junction Schottky Diodes by Electrodeposition of Nano-Structured CuInSe 2 Materials Using Different Upper Electrodes
}

\author{
Jing Liu ${ }^{1}$, Kuo-Wei Liu ${ }^{2}$, Mau-Phon Houng ${ }^{2, *}$ and Cheng-Fu Yang ${ }^{3, *}$ \\ 1 School of Information Engineering, Jimei University, Xiamen 361021, China; jingliu@jmu.edu.cn \\ 2 Institute of Microelectronics, Department of Electrical Engineering, National Cheng Kung University, \\ Tainan City 701, Taiwan; gowayne0327ok@gmail.com \\ 3 Department of Chemical and Materials Engineering, National University of Kaohsiung, Kaohsiung 811, \\ Taiwan \\ * Correspondence: mphoung@eembox.ncku.edu.tw (M.-P.H.); cfyang@nuk.edu.tw (C.-F.Y.)
}

Received: 21 February 2020; Accepted: 10 March 2020; Published: 12 March 2020

check for updates

\begin{abstract}
In this study, CuInSe 2 (CIS) films (CIS-TFs) and nanorods (CIS-NRs) were successfully deposited on $\mathrm{Mo} /$ glass and $\mathrm{p}^{+}$-silicon $\left(\mathrm{p}^{+}-\mathrm{Si}\right)$ using an electrodeposition method. Anodic aluminum oxide (AAO) was used as the template when the CIS-NRs were deposited. $\mathrm{Pt}$, indium tin oxide (ITO), and Ag were deposited as the upper electrodes using a sputtering method to form the hetero-junction devices of Pt/CIS-NRs/ $\mathrm{p}^{+}-\mathrm{Si}$, ITO/CIS-NRs $/ \mathrm{p}^{+}-\mathrm{Si}$, ITO/CIS-TF/Mo/glass, and $\mathrm{Ag} / \mathrm{CIS}-\mathrm{NRs} / \mathrm{p}^{+}-\mathrm{Si}$, respectively. When $\mathrm{p}^{+}-\mathrm{Si}$ was used as the substrate, $\mathrm{Al}$ was deposited on $\mathrm{p}^{+}-\mathrm{Si}$ to form negative electrodes for the devices of $\mathrm{Pt} / \mathrm{CIS}-\mathrm{NRs} / \mathrm{p}^{+}-\mathrm{Si}$, ITO/CIS-NRs $/ \mathrm{p}^{+}-\mathrm{Si}$, and $\mathrm{Ag} / \mathrm{CIS}-\mathrm{NRs} / \mathrm{p}^{+}-\mathrm{Si}$. The current-voltage properties of all the hetero-junction devices were measured and we found that the hetero-junction of ITO/CIS-NRs/ $/ \mathrm{p}^{+}-\mathrm{Si}$, ITO/CIS-TF/Mo/glass, and $\mathrm{Ag} / \mathrm{CIS}-\mathrm{NRs} / \mathrm{p}^{+}-\mathrm{Si}$ devices revealed the properties of Schottky diodes but the hetero-junction device of $\mathrm{Pt} / \mathrm{CIS}-\mathrm{NRs} / \mathrm{p}^{+}-\mathrm{Si}$ device did not. The reason for the cause of the differences between these hetero-junction devices was investigated for this study.
\end{abstract}

Keywords: $\mathrm{CuInSe}_{2}$ (CIS) films and nanorods; electrodeposition method; anodic aluminum oxide; Schottky diode

\section{Introduction}

$\mathrm{CuInSe}_{2}$ (CIS) [1] and $\mathrm{Cu}(\mathrm{In}, \mathrm{Ga}) \mathrm{Se}_{2}$ (CIGS) [2] are the two well-studied materials for photovoltaic (PV) devices because they have high absorption coefficients in the ranges of visible and near-infrared lights, have a direct band gap for electron-hole recombination, and only require a small thickness for light absorption. Many different types of deposition or growth processes have been developed to manufacture the CIS and CIGS absorber layers, and the two-stage process was the most popular method [3]. However, sputtering and co-evaporation are the two most popular vacuum methods to deposit CIS and CIGS films as the absorber layers. For the sputtering method, a reactive co-sputtering using $\mathrm{Cu}_{0.6} \mathrm{Ga}_{0.4}$ and $\mathrm{Cu}_{0.4} \mathrm{In}_{0.6}$ alloys as the targets have been investigated to prepare CIGS films on a $\mathrm{Mo} / g$ lass substrate in association with a thermal cracker for Se radicals [4]. Additionally, CIGS films were prepared by sputtering using a CIGS quaternary alloy as a target, followed by an annealing process [5]. For the co-evaporation method, Ruffenach et al. grew the CIS films using both two-step and three-step processes by co-evaporating different metals in a molecular beam epitaxy system [6]. Lindahl et al. fabricated solar cell devices using the co-evaporation of CIGS films in an inline single-stage process [7]. 
However, different methods of preparing the CIS and CIGS films in non-vacuum processes are also important aspects of technology that have been investigated. Diao et al. investigated a spray coating method (SPM) to prepare a CIS layer on Mo/glass substrates, and the high-densified CIS films were obtained by annealing the prepared films in a selenization furnace [8]. However, electrodeposition was another method used to deposit the CIS and CIGS films in a non-vacuum atmosphere [9-11]. Chang et al. synthesized CIS films by electrodepositing $\mathrm{Cu}$-In-Se precursors using a two-step annealing process. They used a thermal process treating $\mathrm{Cu}$-In precursors to form uniform $\mathrm{Cu}_{11} \mathrm{In}_{9}$ binary compounds. After the Se layer was electrodeposited on the $\mathrm{Cu}_{11} \mathrm{In}_{9}$ layer, an annealing process was employed to form a chalcopyrite CIS compound [12]. Sidali et al. co-electrodeposited the mixed Cu-In-Ga oxides and thermally reduced them into metallic alloys and selenization, then the CIGS films were synthesized [13]. These results suggest that electrodeposition is an easy method to prepare CIS and CIGS alloys, and we used it to grow the CIS films and nanorods.

These results also suggest that when CIS and CIGS films are synthesized using a non-vacuum method, the annealing or thermal treatment processes are very important to enhance their crystallization and form a chalcopyrite compound. For this, we also decided to use the annealing process to enhance the crystallization of the prepared CIS alloy. In the past, Chiang et al. used a polymer-type ion release source and they used a hydrothermal system to grow CIS nanowires by controlling the precursor concentration [14]. Thus, we used cyclic voltammetry as the method, anodic aluminum oxide (AAO) as a template, and $\mathrm{Bi}\left(\mathrm{NO}_{3}\right)_{3}-5 \mathrm{H}_{2} \mathrm{O}, \mathrm{SbCl}_{3}$, and $\mathrm{TeCl}_{4}$ as the ions' sources to grow $(\mathrm{Bi}, \mathrm{Sb})_{2-\mathrm{x}} \mathrm{Te}_{3+\mathrm{x}}$-based nanowires. [15]. For this, the first subject of our research was to grow CIS films (CIS-TFs) and nanorods (CIS-NRs) using an electrodeposition method, and AAO was used as a template for growing the CIS-NRs. A Schottky diode could be easily fabricated by deposition of a pure Al electrode on the $\mathrm{CuInSe}_{2}$ film [16]. The second subject of our research was to use different conduction materials as the upper electrodes. We showed that Pt/CIS-NRs is an ohmic contact and indium tin oxide (ITO)/CIS-NRs, ITO/CIS-TF, and Ag/CIS-NRs are the Schottky contact and their J-V characteristics were also well investigated.

\section{Materials and Methods}

In this study, hetero-junction devices with four different structures were investigated, as shown in Figure 1. We first took Pt/CIS-NRs $/ \mathrm{p}^{+}-\mathrm{Si}$ (Figure 1a), which used $\mathrm{Pt}$ as upper electrode, and we found that the Pt/CIS-NRs contact formed the ohmic contact rather than the Schottky contact. The other structures were ITO/CIS-NRs/ $\mathrm{p}^{+}-\mathrm{Si}$ (Figure 1b), ITO/CIS-TF/Mo/glass (Figure 1c), and Ag/CIS-NRs $/ \mathrm{p}^{+}-\mathrm{Si}$ (Figure 1d), respectively. We demonstrated that the three devices revealed the characteristics of a Schottky diode, and their current-voltage properties depended on the contact electrode and the structure of $\mathrm{CuInSe}_{2}$ nanomaterials.
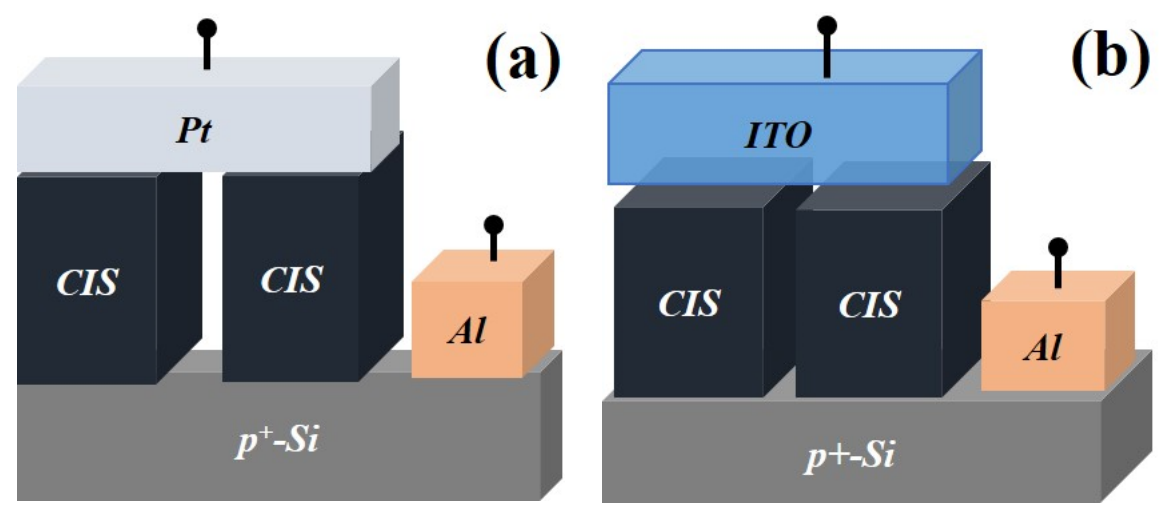

Figure 1. Cont. 

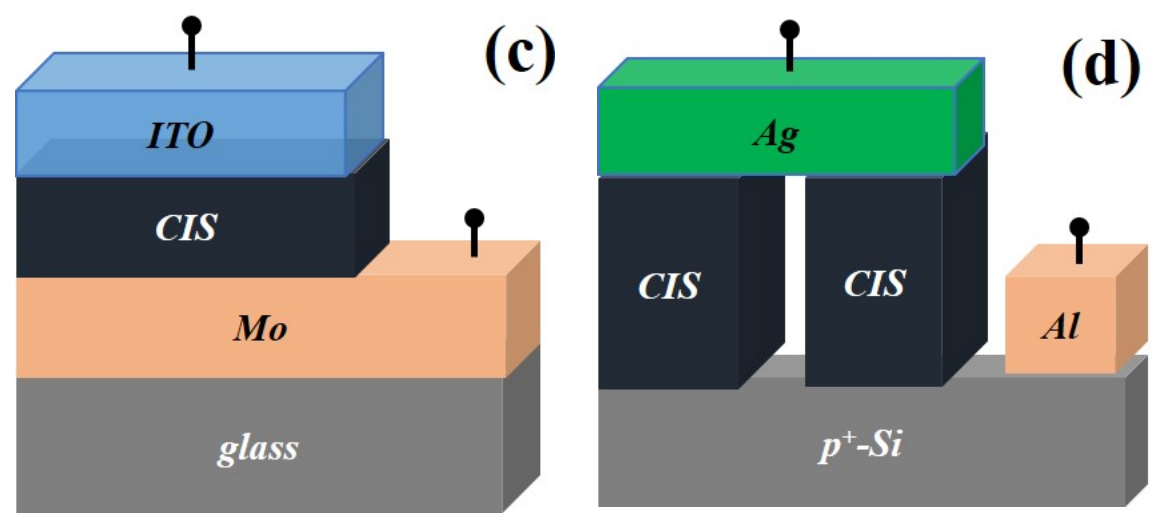

Figure 1. Structures of prepared hetero-junction devices (a) Pt/CIS-NRs $/ \mathrm{p}^{+}-\mathrm{Si}$, (b) ITO/CIS-NRs/ $\mathrm{p}^{+}-\mathrm{Si}$, (c) ITO/CIS-TF/Mo/glass, and (d) Ag/CIS-NRs/p ${ }^{+}-\mathrm{Si}$. CIS-NRs, CuInSe 2 nanorods; ITO, indium tin oxide; CIS-TF, CuInSe ${ }_{2}$ film.

$\mathrm{CuCl}_{2} \cdot 2 \mathrm{H}_{2} \mathrm{O}$ ( $\geq 99 \%$, Sigma-Aldrich, St. Louis, MI, USA), $\mathrm{InCl}_{3}$ (99.99\%, Alfa Aesar, Ward Hill, MA, USA), $\mathrm{H}_{2} \mathrm{SeO}_{3}$ (98\%, Sigma-Aldrich), $\mathrm{LiCl}$ (99\%, Alfa Aesar), and dimethyl sulfoxide ( $\geq 99 \%$, DMSO, J.T. Baker) were used as the source solutions to deposit the CIS films and CIS nanowires. The potentiostat was used to provide the stable pulse voltage source with constant electric potential for the electrodeposition of nano-structured CIS materials. The p-Si substrates, Pt-Ti net, and reference (saturated calomel) electrode formed the three-electrode electrodeposition system. AAO was used as the template when the CIS-NRs were deposited. The solution included $\mathrm{CuCl}_{2} 1.5 \mathrm{mM}, \mathrm{InCl}_{3} 25$ $\mathrm{mM}$, and $\mathrm{H}_{2} \mathrm{SeO}_{3} 3 \mathrm{mM}$, where $\mathrm{LiCl} 0.7 \mathrm{M}$ was added to enhance the conductivity of the solution and DMSO 0.1 M was used as a surface modifier. The DMSO was used to coat the surface of the AAO template to reduce its surface polarity, caused by the positive charge, to enhance the process of filling the hole. The optimum electrodeposition parameters were of a duty cycle of $33 \%\left(T_{\text {on }}=1 \mathrm{~s}\right.$ and $T_{\text {off }}=2$ $\mathrm{s})$, deposition temperature of $35^{\circ} \mathrm{C}, \mathrm{pH}$ value of 1.5 , deposition voltage of $-1.6 \mathrm{~V}$, and deposition time of $5 \mathrm{~min}$. Figure $2 \mathrm{a}$ shows the variations of current and voltage during the first cycle and Figure $2 \mathrm{~b}$ shows the variation of current during the whole deposition process ( $0 \sim 300 \mathrm{~s})$, respectively. They show that the deposition process was a pulsed electrodeposition with a duty cycle of $33 \%$.

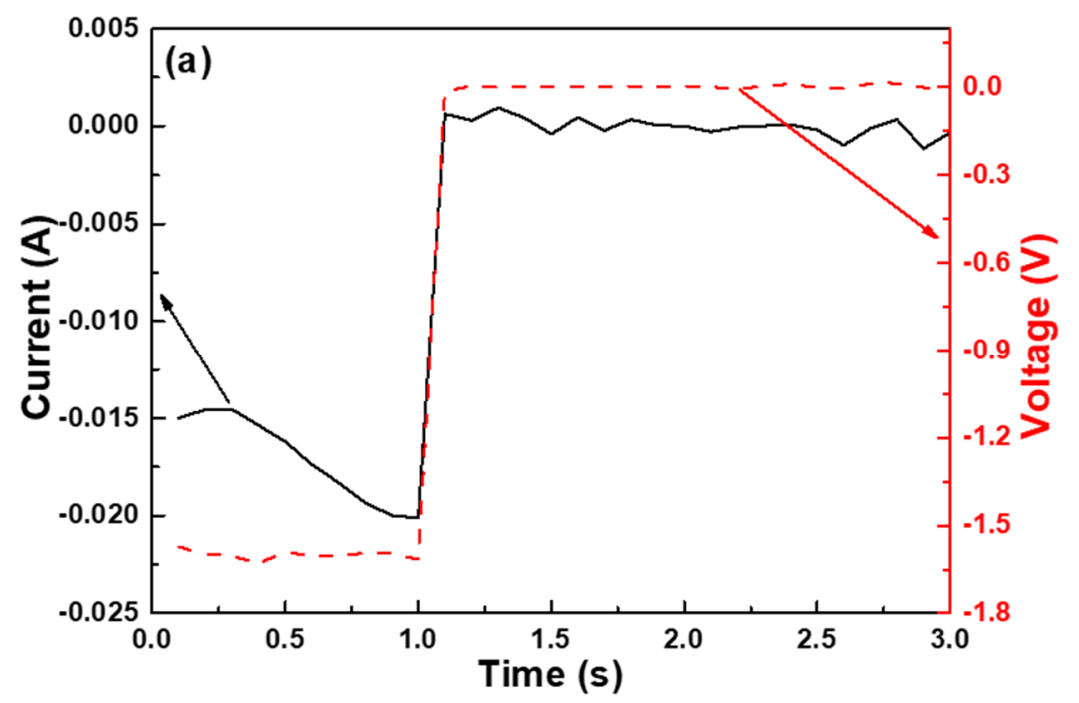

Figure 2. Cont. 


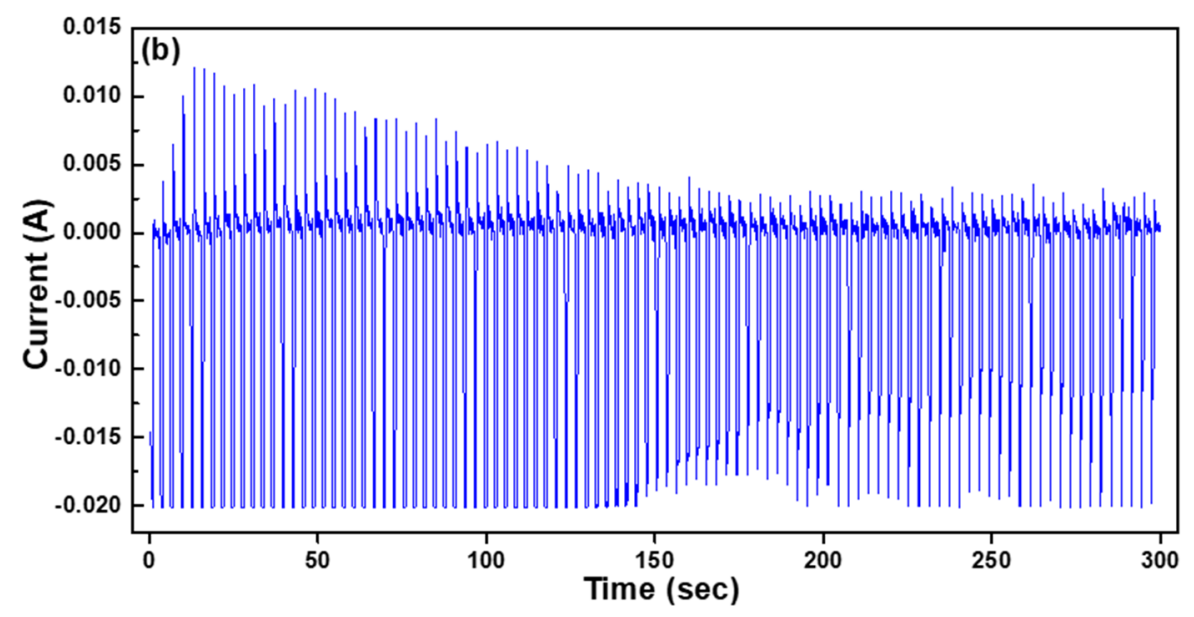

Figure 2. (a) The variations of current and voltage during the first cycle and (b) the variation of current during the whole deposition process (0 300 s).

After the deposition process, the CIS films and CIS-NRs in the AAO templates were annealed at $250{ }^{\circ} \mathrm{C}$ for $15 \mathrm{~min}$ and then annealed at $450{ }^{\circ} \mathrm{C}$ for $15 \mathrm{~min}$. The annealing process enhanced the crystallization, and made the CuSe phase melt and react with the CuInSe $e_{2}$ to obtain the CuInSe $e_{2}$ with a chemical dose close to 1:1:2, that is, the preferred crystal phase. The AAO template was removed using $0.6 \mathrm{M}$ phosphoric acid solution at $30{ }^{\circ} \mathrm{C}$ for $2 \mathrm{~h}$. Finally, the $\mathrm{KCN}$ solution was used to etch the disk-typed $\mathrm{Cu}$-rich or In-rich films, which were residual on the surfaces of the CIS-NRs. The Pt electrode was deposited using the direct current (DC) sputter in a pure Ar atmosphere. The ITO electrode was deposited using the DC sputter and the deposition parameters were as follows: Ar flow rate of $30 \mathrm{sccm}, \mathrm{O}_{2}$ flow rate of $0.8 \mathrm{sccm}$, deposition power of $100 \mathrm{~W}$, deposition time of $60 \mathrm{~min}$, and deposition temperature of $100{ }^{\circ} \mathrm{C}$. The ITO electrode deposited at these parameters had a resistivity of $1.08 \times 10^{-3} \Omega \cdot \mathrm{cm}$ and an average transmittance ratio $(400 \sim 700 \mathrm{~nm})$ of $91.68 \%$. The morphologies of CIS nanomaterials were measured using a field emission scanning electron microscopy (FESEM), while nano-scale analyses of CIS nanomaterials were performed using transmission electron microscope (TEM). The crystalline structures of CIS nanomaterials were identified using X-ray diffraction (XRD) patterns with $\mathrm{Cu} \mathrm{K} \alpha$ radiation.

\section{Results}

Figure 3 shows the diffraction characteristic peaks of the deposited CIS films and nanorods. Diffraction peaks at $2 \theta$ values of $26.61^{\circ}, 44.20^{\circ}, 52.32^{\circ}$, and $64.34^{\circ}$, which correspond to the diffraction planes of (112), (220/204), (312/116), and (400), were observed for the CIS phase. As the XRD pattern in Figure 1 shows, the diffraction intensity of the CIS films was higher than that of the CIS-NRs. In addition, the full width at half maximum (FWHM) value of the (004) plane for the CIS films was smaller than that of the CIS-NRs. There are two reasons why the diffraction intensity of the CIS films was larger than that of the CIS-NRs. The first is that the crystallization of the CIS films is better than that of the CIS-NRs and the second is that the effective diffraction surface of the CIS films is larger than that of the CIS-NRs. Because the FWHM value of the CIS films is smaller than that of the CIS-NRs, we believe the better crystallization of the CIS films is the main reason for the difference in the diffraction intensities of CIS films and the CIS-NRs. However, both the deposited CIS films and the CIS-NRs have high crystallization for further applications of devices. 


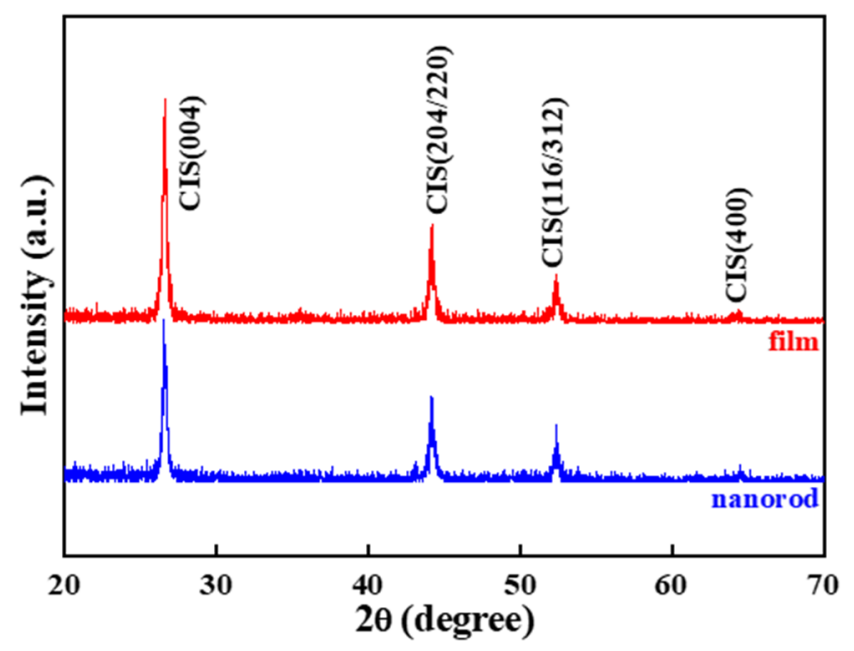

Figure 3. XRD patterns of deposited CIS films and nanorods.

Figure 4 shows the SEM images of deposited CIS films on the surface of the $\mathrm{Mo} / \mathrm{Si}^{+}$substrate. Figure 4a shows that the CIS films had rough surfaces and a micro-crystalline structure and that the grain-size distributed from $\sim 0.5 \mu \mathrm{m}$ to $\sim 1.6 \mu \mathrm{m}$. Figure $4 \mathrm{~b}$ shows that the thicknesses of the Mo electrode and CIS films were about $800 \mathrm{~nm}$ and $1.21 \mu \mathrm{m}$. In contrast, Figure 4a shows the corresponding SEM images of deposited CIS films, and the elemental maps of CIS films were obtained by FESEM equipped with Energy Dispersive Spectrometer (EDX) for elemental $\mathrm{Cu}$, In, and Se (not shown here). The elemental ratio of Cu:In:Se was about 27.90 (27.74 28.09):26.67 (26.51 26.88):45.43 (45.26 45.67), which was close to the ideal chemical ratio of 1:1:2. Because the $\mathrm{Se} /(\mathrm{Cu}+\mathrm{In})$ ratio is smaller than 1 and the $\mathrm{Cu} / \mathrm{In}$ ratio is larger than 1, the deposited CIS films had the properties of a p-type [17]. The deposited film showed that it was richer in $\mathrm{Cu}$ than In, and it was the p-type CIS films.
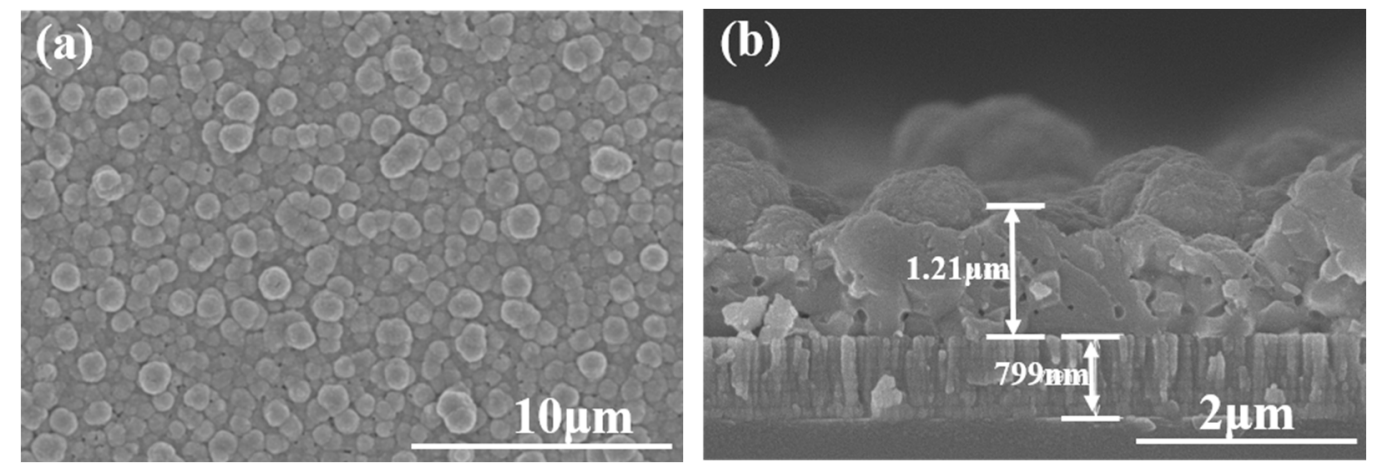

Figure 4. SEM images of the deposited CIS films: (a) surface and (b) cross-section observations.

A cross-sectional SEM image, a cross-sectional high-resolution transmission electron microscopy (HRTEM) image and TEM diffraction analysis of the CIS-NRs deposited on $\mathrm{p}^{+}$-Si substrate are shown in Figure 5. For the CIS-NRs, as Figure 5a shows, the deposited nanorods expanded epitaxially on the $\mathrm{p}^{+}-\mathrm{Si}$ substrate and their height was about $335 \mathrm{~nm}$. The SEM analysis also found that the average particle size of the CIS-NRs was about $34.6 \mathrm{~nm}$. The elemental maps of the CIS-NRs were also obtained by FESEM equipped with EDX for elemental $\mathrm{Cu}$, In, and Se, and the elemental ratio of $\mathrm{Cu}: \mathrm{In}$ :Se was about 28.17:21.21:50.62. Even the $\mathrm{Se} /(\mathrm{Cu}+\mathrm{In})$ was larger than 1, but $\mathrm{Cu} / \mathrm{In}$ was also larger than 1; therefore, the deposited CIS-NRs also revealed the properties of the p-type [17]. To identify the microstructures, the HRTEM cross-sectional observation and nano-beam diffraction analyses were taken from the grown CIS-NRs, and the results are shown in Figure 5b,c. From the HRTEM image in Figure $4 \mathrm{~b}$, we found that the lattice spacing and lattice constant were 0.334 and $0.578 \mathrm{~nm}$, respectively. The lattice parameters of deposited CIS-NRs calculated from the XRD patterns were $a=0.5808 \pm 0.0003$ 
$\mathrm{nm}$ and $c=1.159 \pm 0.004 \mathrm{~nm}$, which was the strongest match with the lattice constant observed using HRTEM. The measured lattice spacing of the CIS-NRs stem was $0.334 \mathrm{~nm}$, which was also the strongest match with the hexagonal bismuth crystal structure and conformed with CuInSe ${ }_{2}$ chalcopyrite (112) d-spacing. From the TEM diffraction analyses in Figure 5c, we also found that the lattice distance matched the preferred crystal phase of the (112) plane.

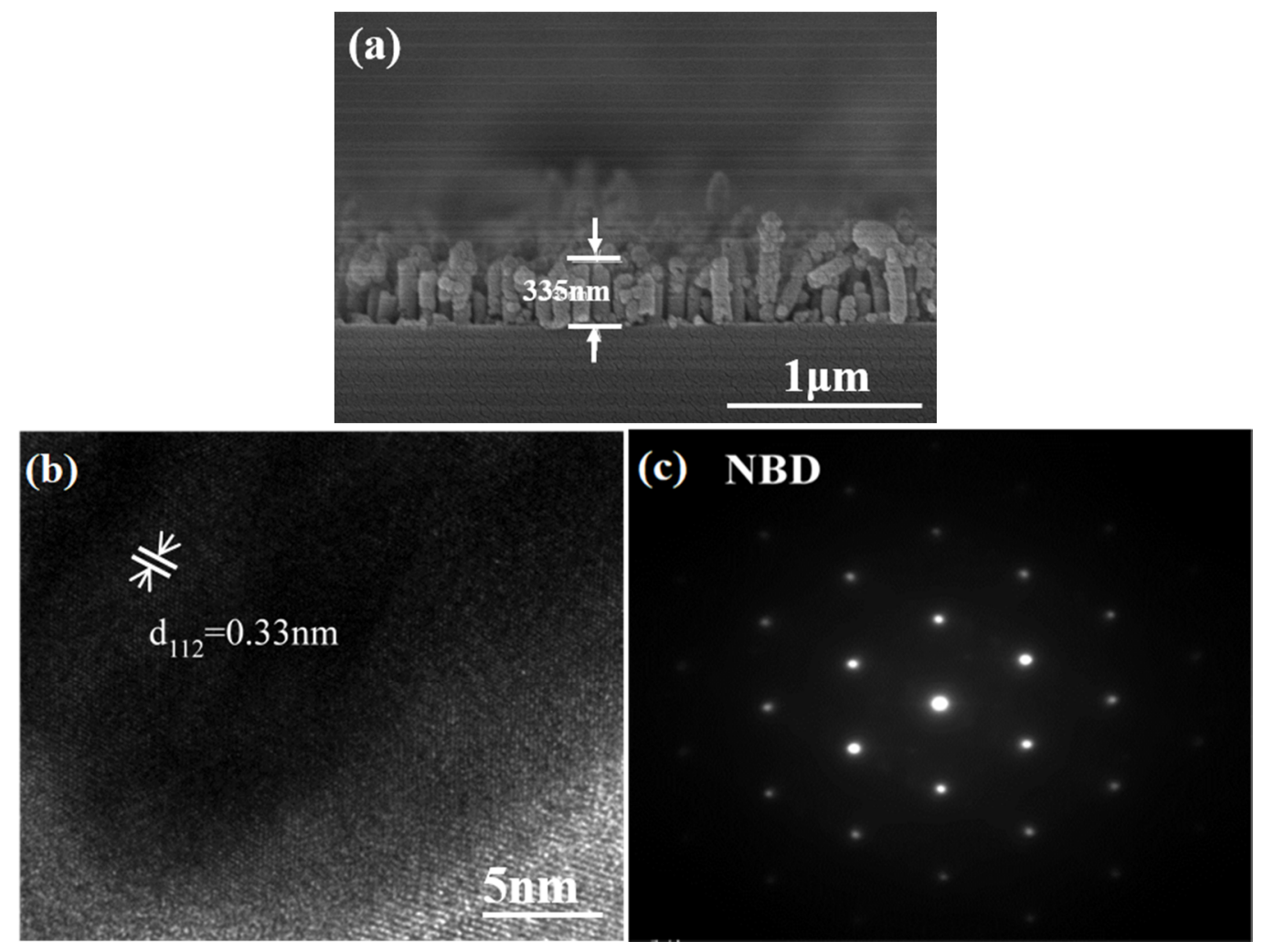

Figure 5. The CIS-NRs: (a) SEM images (b) high magnification TEM, and (c) nano-beam diffraction.

In the past, Capon et al. deposited $\mathrm{CuInSe}_{2}$ films that were obtained by selenization of ternary $\mathrm{CuInSe}_{2}$ nanocrystals and mixtures of binary nanocrystals such as $\mathrm{Cu}_{2} \mathrm{Se}$ and $\mathrm{In}_{2} \mathrm{Se}_{3}$. They investigated the d-spacing as a function of selenization time by fitting the raw in situ XRD data of the (112) diffraction peak. They found that the XRD pattern of the CuInSe $\mathrm{C}_{2}$ films depicted a lattice spacing of $\sim 0.335 \mathrm{~nm}$ that corresponded to the distance between the (112) planes, indicating a good orientation along the (112) plane [18]. Rincon and Ramlrez used the vertical Bridgman method to prepare the CuInSe 2 crystal and they found that a single phase with a chalcopyrite structure was present in the CuInSe 2 crystal with lattice parameters of $a=0.5873 \mathrm{~nm}$ and $c=1.1583 \mathrm{~nm}$ [19]. Mobarak et al. used two different methods to prepare the CuInSe 2 compound and they found that the mean values of the lattice constants of the crystal prepared by the Bridgman method were $a=0.57823 \mathrm{~nm}$ and $c=1.16192 \mathrm{~nm}$, whereas those of the crystal grown by the traveling heater method were $a=0.5787 \mathrm{~nm}$ and $c=1.1574$ $\mathrm{nm}$, respectively [20]. These results show that our prepared CIS samples have the good crystallinity with a chalcopyrite structure and a good orientation along the (112) plane.

The Schottky diode, which is also referred to as the Schottky barrier diode or hot-carrier diode, is a hetero-junction semiconductor diode formed by the contact of a semiconductor with a metal. For a typical Schottky diode, the used metal will act as the anode and the n-type semiconductor will act as the cathode, which means the current can flow from the metal side to the semiconductor side, but it cannot flow in the opposite direction. The different combinations of the metals and semiconductors can affect the forward voltage of the constructed diodes, and both $\mathrm{n}$ - and p-type semiconductors can 
develop as the Schottky barriers. However, the p-type typically can be used to fabricate a Schottky diode with a much lower forward voltage.

In this study, the work function of $\mathrm{Al}\left(\Phi_{\mathrm{Al}}\right)$ is about $4.28 \mathrm{eV}$ and that of $\mathrm{p}^{+}-\mathrm{Si}\left(\Phi_{\mathrm{p}+\mathrm{Si}}\right)$ is in the range of $4.61 \sim 5.17 \mathrm{eV}$. From the theorem in Figure 6, the $\mathrm{Al} / \mathrm{p}^{+}-\mathrm{Si}$ contact should be the Schottky contact. However, before the electrodeposition process, we first annealed the $\mathrm{Al} / \mathrm{p}^{+}-\mathrm{Si}$ contact at a high temperature, then $\mathrm{Al}$ was diffused onto the surface of the $\mathrm{p}^{+}-\mathrm{Si}$ wafer. This process caused an increase in the doping concentration of the contact interface and reduced the width of the depletion region. This resulted in the electrons and holes tunneling the junction barrier and then the ohmic contact formed. The typical dark current-voltage (J-V) characteristic of the Pt/CIS-NRs $/ \mathrm{p}^{+}$-Si hetero-junction device is displayed in the Figure 6, where Figure 6a,b shows the normal scale and the log scale, respectively. The work function of CIS ( $\left.\Phi_{\mathrm{CIS}}\right)$ is about $5.1 \mathrm{eV}$ and that of $\mathrm{Pt}\left(\Phi_{\mathrm{Pt}}\right)$ is $5.65 \mathrm{eV}$. From the theorem in Figure 6, the CIS/Pt contact should be the ohmic contact. The J-V curves of the Pt/CIS-NRs/ $\mathrm{p}^{+}-\mathrm{Si}$ device in normal scale (Figure $6 \mathrm{a}$ ) and log scale (Figure $6 \mathrm{~b}$ ) show that the CuInSe $/ \mathrm{p}^{+}-\mathrm{Si}$ produced symmetrical results, which show that all the interfaces of the Pt/CIS-NRs $/ \mathrm{p}^{+}-\mathrm{Si}$ device had ohmic contact.
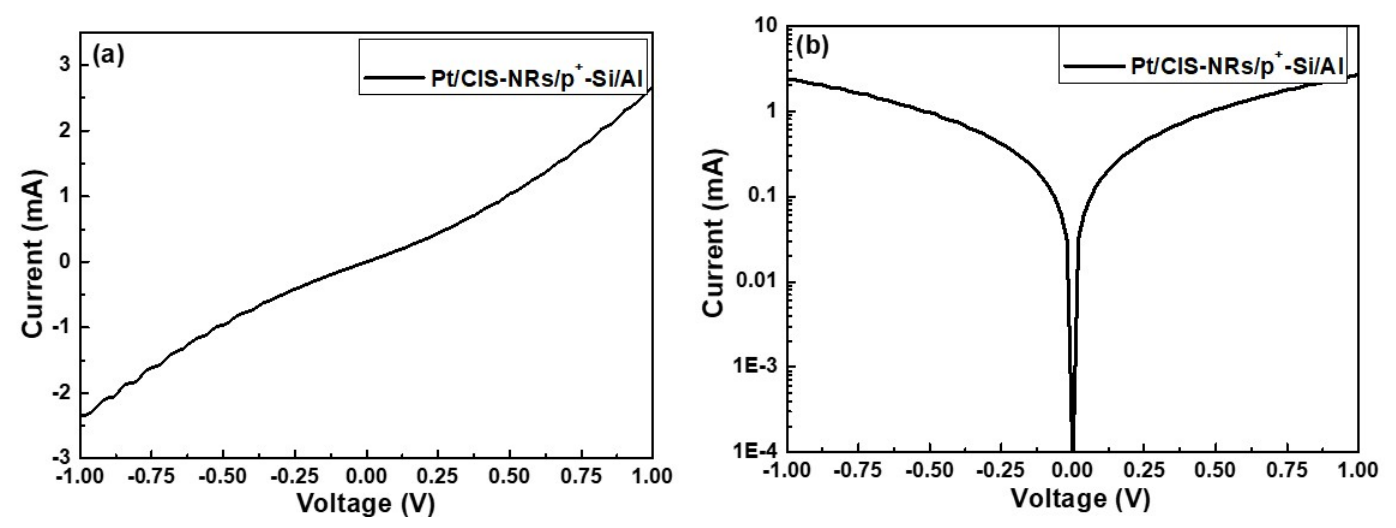

Figure 6. J-V curve of the Pt/CIS-NRs/p+ ${ }^{+}$-Si device: (a) normal scale and (b) log scale.

The J-V curves of the ITO/CIS-NRs/ $\mathrm{p}^{+}-\mathrm{Si}$ device are shown in Figure $7 \mathrm{a}, \mathrm{b}$ for the normal scale and the log scale, respectively, which shows that the J-V curves were not symmetrical. When $+1 \mathrm{~V}$ and $-1 \mathrm{~V}$ were used as the standard to measure the current densities, the forward and reverse current densities were $0.35 \mathrm{~mA} / \mathrm{cm}^{\mathrm{a}}$ and $-0.165 \mathrm{~mA} / \mathrm{cm}^{2}$, respectively, and the on/off ratio was 2.12 . These results suggest that the interface of the ITO/CIS-NRs is a Schottky contact and the ITO/CIS-NRs $/ \mathrm{p}^{+}-\mathrm{Si}$ device can act as a Schottky diode. For the ITO/CIS-TF/Mo device, when $+1 \mathrm{~V}$ and $-1 \mathrm{~V}$ were used as the standard to measure the current densities, the forward and reverse current densities were $189.3 \mathrm{~mA} / \mathrm{cm}^{2}$ and $-47.51 \mathrm{~mA} / \mathrm{cm}^{2}$, respectively. Figure $8 \mathrm{a}, \mathrm{b}$ shows the normal scale and the log scale, respectively, and the on/off ratio for these scales was 3.98. These results also suggest that the interface of ITO/CIS-TF is a Schottky contact.

For the ITO/CIS-TF/Mo device, its current densities of forward bias and reverse bias were higher than those of the ITO/CIS-NRs $/ \mathrm{p}^{+}-\mathrm{Si}$ device, and there are two possible reasons for these results. First, the contact interface of ITO/CIS-TF was larger and had better contact than that of the ITO/CIS-NRs device, and second, the contact interface of the CIS-TF/Mo was larger and had better contact than that of the CIS-NRs $/ \mathrm{p}^{+}-\mathrm{Si}$ device. The interfaces between the CIS-NRs $/ \mathrm{p}^{+}-\mathrm{Si}$ and CIS-TF/Mo were caused by the ohmic contact, therefore the Schottky effect was caused by the contact of the ITO/CIS-NRs and the ITO/CIS-TF. So far, the work function of ITO is not exactly defined. Chkoda et al. used photoelectron spectroscopy to measure the work function of commercial ITO, and their measured values were dependent on the cleaning air of substrates. When the glass substrate was cleaned by organic solvents, the $\Phi_{\text {ITO }}$ was 3.9-4.2 $\pm 0.1 \mathrm{eV}$ and when the glass substrate was cleaned by $\mathrm{Ar}^{+}$ sputtering, the $\Phi_{\text {ITO }}$ was $4.3 \pm 0.1 \mathrm{eV}$ [21]. Beerbom et al. used photoemission spectroscopy and an ultra-high vacuum Kelvin probe to measure the work function of commercial ITO films on glass 


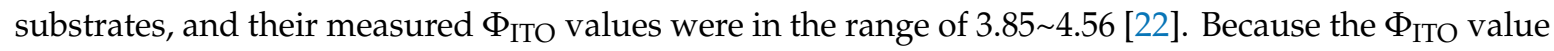
was smaller than the $\Phi_{\text {CIS }}$ value, there is no doubt that the Schottky effect was caused by the contact of the ITO/CIS-NRs and the ITO/CIS-TF.
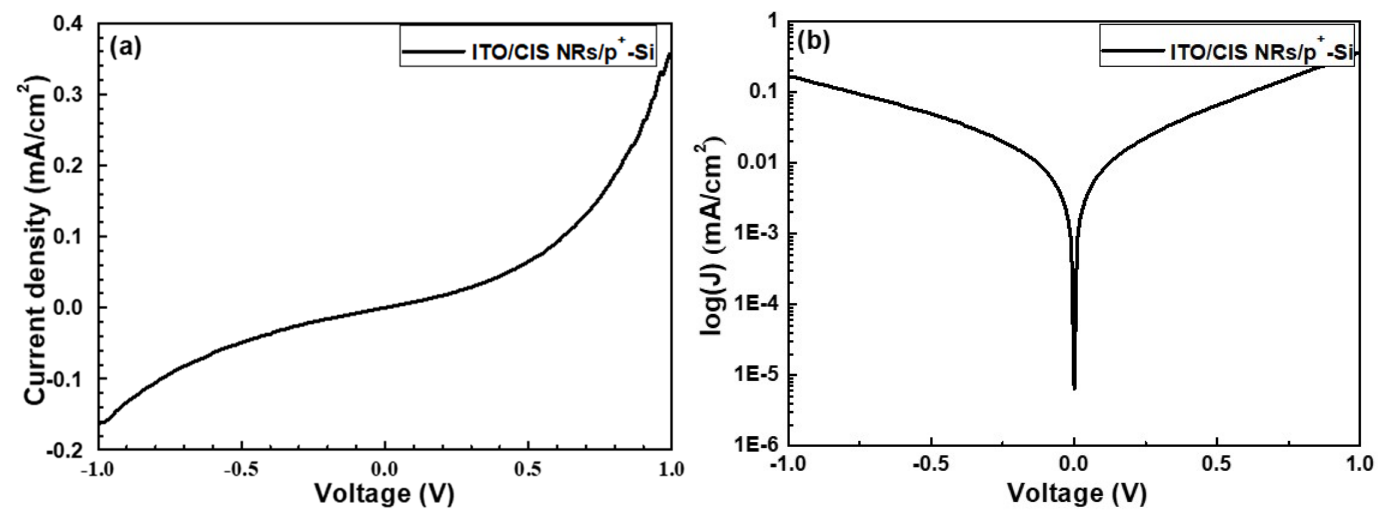

Figure 7. J-V curve of the ITO/CIS-NRs/p+ ${ }^{+}$-Si device: (a) normal scale and (b) log scale.
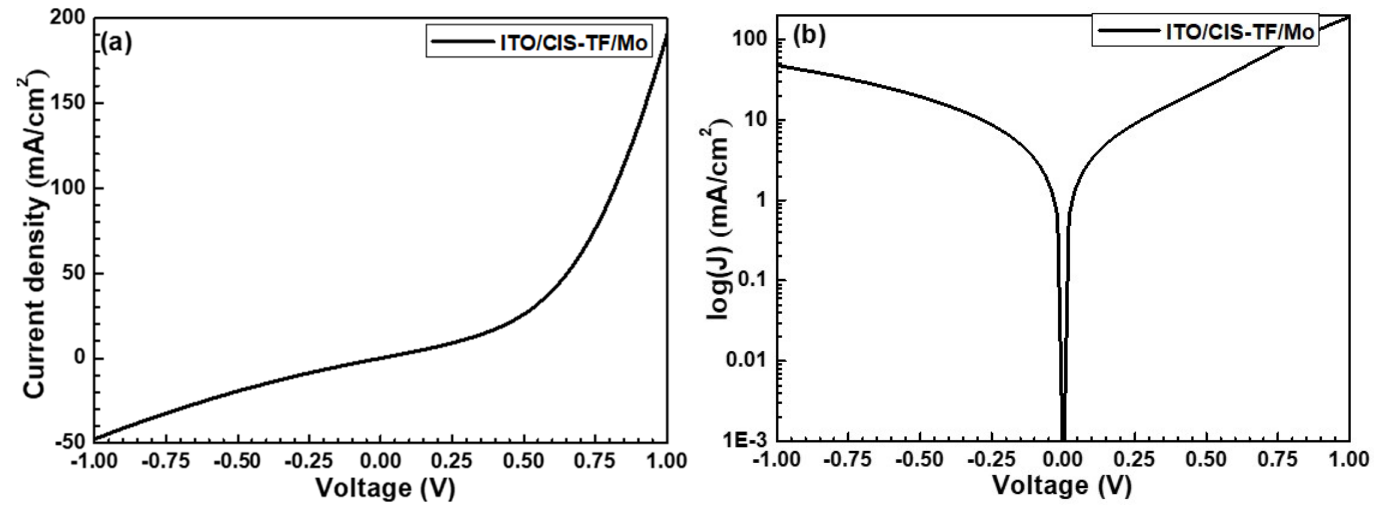

Figure 8. J-V curve of the ITO/CIS-TF/Mo device: (a) normal scale and (b) log scale.

Finally, Ag was used as the electrode to form the $\mathrm{Ag} / \mathrm{CIS}-\mathrm{NRs} / \mathrm{p}^{+}-\mathrm{Si}$ structure, and its $\mathrm{J}-\mathrm{V}$ characteristic was also measured. The $\Phi_{\mathrm{Ag}}$ was $4.26 \mathrm{eV}$, which was smaller than the $\Phi_{\mathrm{CIS}}$ value and the Ag/CIS-NRs $/ \mathrm{p}^{+}-\mathrm{Si}$ device formed the Schottky diode. Figure $9 \mathrm{a}, \mathrm{b}$ shows the normal scale and $\log$ scale, respectively. For the Ag/CIS-NRs/ $/ \mathrm{p}^{+}-\mathrm{Si}$ device, when $+1 \mathrm{~V}$ and $-1 \mathrm{~V}$ were used as the standard to measure the current densities, the forward and reverse current densities were $0.48 \mathrm{~mA} / \mathrm{cm}^{2}$, $-0.06 \mathrm{~mA} / \mathrm{cm}^{2}$, respectively, and the on/off ratio was 8.07 . These results show that interface of the $\mathrm{Ag} / \mathrm{CIS}-\mathrm{NRs}$ was a Schottky contact and the Ag/CIS-NRs/ $/ \mathrm{p}^{+}-\mathrm{Si}$ device acted as a Schottky diode.
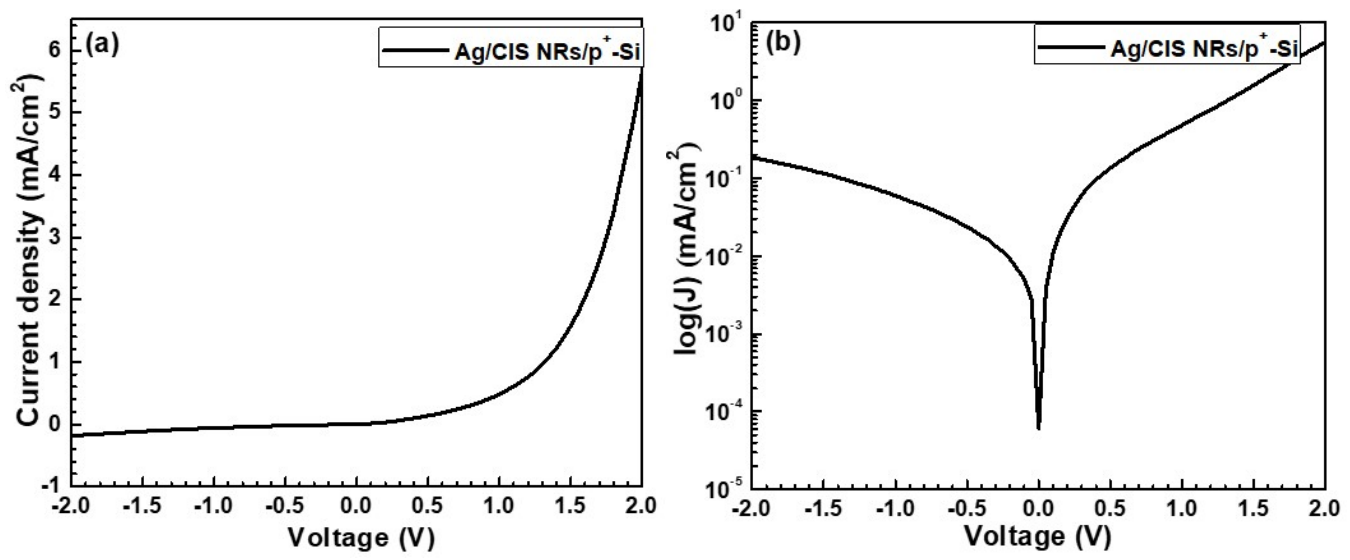

Figure 9. J-V curve of the Ag/CIS-NRs/p ${ }^{+}-S i$ diode: (a) normal scale and (b) log scale. 
In this study, the $\mathrm{Ag} / \mathrm{CIS}-\mathrm{NRs} / \mathrm{p}^{+}-\mathrm{Si}$ diode had the larger on/off ratio, therefore its $\mathrm{C}-\mathrm{V}$ characteristic was also measured and the results are shown in Figure 10a, and the relationship for $1 / \mathrm{C}^{2}-\mathrm{V}$ is shown in Figure $10 \mathrm{~b}$. The $1 / \mathrm{C}^{2}$ can be used to find the built voltage $\left(V_{b i}\right)$ of the Ag/CIS-NRs/ $\mathrm{p}^{+}-\mathrm{Si}$ diode, and the Equation for the relationship between $1 / C^{2}$ and $V_{b i}$ is shown in Equation (1). Because the slope shown in Figure 10b is positive, this shows that the CIS-NRs is a p-type semiconductor. From the extrapolation line of the slope, the $V_{b i}$ can be found at the intercept of the slope and voltage axis, and $V_{b i}$ is $0.22 \mathrm{~V}$. The parameter $\epsilon_{r}$ was used to measure $\epsilon_{S}$ and was obtained from [23], where $\epsilon_{S}=\epsilon_{0} \epsilon_{r}=$ $8.85 \times 10^{-14} \times 13.5 \mathrm{~F} / \mathrm{cm}=1.19475 \times 10^{-12} \mathrm{~F} / \mathrm{cm}$ and $N_{\mathrm{V}}=1.5 \times 10^{19} \mathrm{~cm}^{-3}$. The relationships to find the Schottky barrier $\left(\Phi_{\mathrm{SH}}\right)$ and the carrier concentration $\left(N_{A}\right)$ of the CIS-NRs can be expressed in Equations (2) and (3). When we brought $V_{b i}=0.22 \mathrm{~V}$ into Equations (2) and (3), the calculated $\Phi_{\mathrm{SH}}$ value was 0.7 $\mathrm{V}$ and the calculated $N_{A}$ value was $1.38 \times 10^{11} \mathrm{~cm}^{-3}$.

$$
\begin{gathered}
\frac{1}{C^{2}}=\frac{2\left(V_{b i}+V\right)}{q N \epsilon_{S}} \\
\Phi_{S H}=V_{b i}-\frac{K T}{q} \ln \frac{N_{A}}{N_{V}} \\
N_{A}=\frac{2}{q \epsilon_{s} \frac{d\left(\frac{1}{c^{2}}\right)}{d V}}=\frac{2}{q \epsilon_{s} \cdot \text { slope }}
\end{gathered}
$$
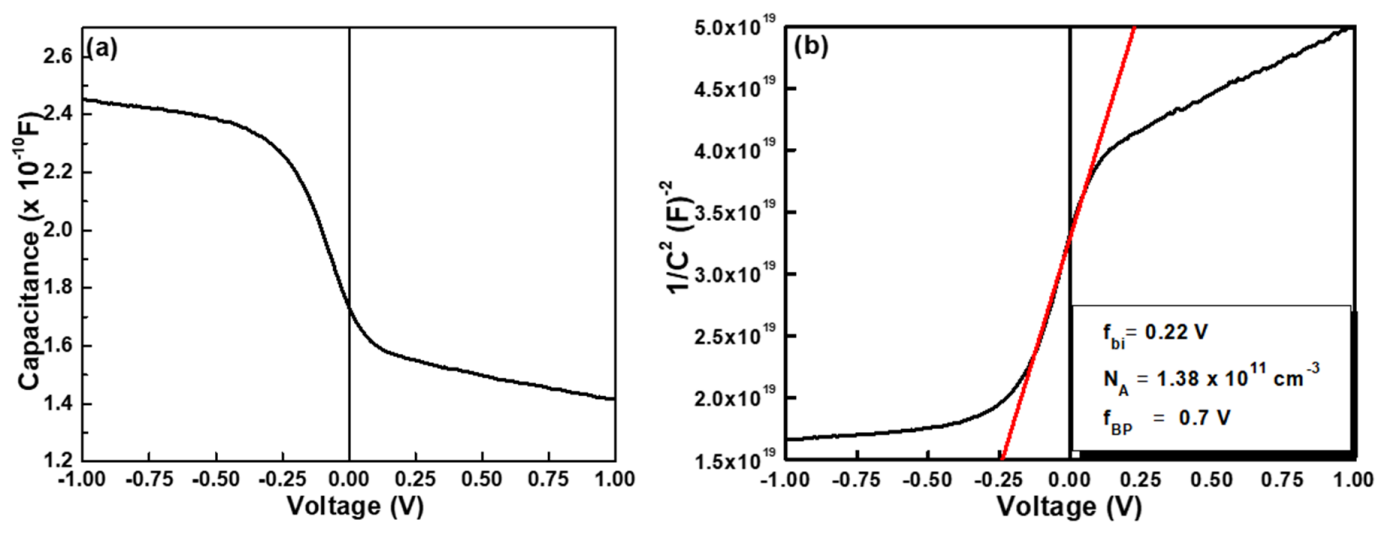

Figure 10. (a) C-V curve and (b) $1 / C^{2}-V$ curve of the Ag/CIS-NRs $/ \mathrm{p}^{+}-\mathrm{Si}$ diode.

Because the Ag/CIS-NRs $/ \mathrm{p}^{+}-\mathrm{Si}$ diode has the maximum on/off ratio of 8.07, we used its properties to compare the performance of the Schottky diodes with those fabricated with other techniques. Tecimer et al. used a thermal evaporation method to synthesize CuInSe $e_{2}$ films on a Mo-coated glass substrate, and the carrier concentration of the deposited CuInSe $e_{2}$ films was $4.0 \times 10^{17} \mathrm{~cm}^{-3}$. After the CuInSe $e_{2}$ films were deposited, $\mathrm{Al}$ metal was evaporated on the upper surface of the CuInSe ${ }_{2}$

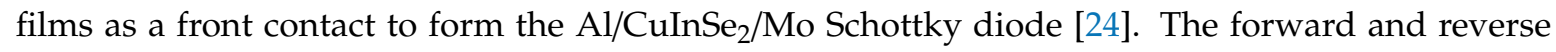
current densities of the $\mathrm{Al} / \mathrm{CuInSe}_{2} / \mathrm{Mo}$ Schottky diode (measured at $300 \mathrm{~K}$ and at $+1 \mathrm{~V}$ and $-1 \mathrm{~V}$ ) were $\sim 0.42 \mathrm{~mA} / \mathrm{cm}^{2}$ and $\sim-0.07 \mathrm{~mA} / \mathrm{cm}^{2}$, the on/off ratio was $\sim 6$, and the $\Phi_{\mathrm{SH}}$ value was $0.729 \mathrm{~V}$. Hamrouni et al. electrodeposited the CuInSe $e_{2}$ films on FTO substrates and annealed them at $400{ }^{\circ} \mathrm{C}$ in a vacuum for a duration of $20 \mathrm{~min}$, and the carrier concentration of deposited $\mathrm{CuInSe}_{2}$ films at $300 \mathrm{~K}$ was $8.66 \times$ $10^{15} \mathrm{~cm}^{-3}$. Additionally, Al metal was evaporated on the upper surface of the CuInSe $\mathrm{C}_{2}$ film as a front

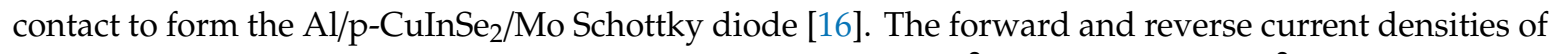
the $\mathrm{Al} / \mathrm{CuInSe} / \mathrm{Mo}$ Schottky diode (at $300 \mathrm{~K}$ ) were $0.151 \mathrm{~mA} / \mathrm{cm}^{2}$ and $-0.038 \mathrm{~mA} / \mathrm{cm}^{2}$, respectively, the on/off ratio was 3.98 , and the $\Phi_{\mathrm{SH}}$ value was $\sim 1.22 \mathrm{~V}$. As compared with the two $\mathrm{Al} / \mathrm{p}-\mathrm{CuInSe} / \mathrm{Mo}$ Schottky diodes, even our deposited CIS films had the lower value of carrier concentration $\left(\mathrm{N}_{\mathrm{A}}\right)$, and 
our investigated $\mathrm{Ag} / \mathrm{CIS}-\mathrm{NRs} / \mathrm{p}^{+}$-Si diode had the larger forward current density of $0.48 \mathrm{~mA} / \mathrm{cm}^{2}$ and an on/off ratio of 8.07 .

\section{Conclusions}

In this study, the hetero-junction of ITO/CIS/p $\mathrm{p}^{+}-\mathrm{Si}$, ITO/CIS/Mo/glass, and Ag/CIS/ $\mathrm{p}^{+}-\mathrm{Si}$ devices revealed the properties of Schottky diodes but the hetero-junction device of the $\mathrm{Pt} / \mathrm{CIS} / \mathrm{p}^{+}$-Si device did not. One possible reason is that $\Phi_{\text {ITO }}$ and $\Phi_{\mathrm{Ag}}$ are smaller than $\Phi_{\mathrm{CIS}}$ but $\Phi_{\mathrm{Pt}}$ is larger than $\Phi_{\text {CIS }}$. When $+1 \mathrm{~V}$ and $-1 \mathrm{~V}$ were used as the standard, the forward and reverse current densities of ITO/CIS-NRs $/ \mathrm{p}^{+}-\mathrm{Si}$, ITO/CIS-TF/Mo/glass, and Ag/CIS-NRs $/ \mathrm{p}^{+}$-Si devices were $0.35 \mathrm{~mA} / \mathrm{cm}^{2}$ and $-0.165 \mathrm{~mA} / \mathrm{cm}^{2}, 189.3 \mathrm{~mA} / \mathrm{cm}^{2}$ and $-47.51 \mathrm{~mA} / \mathrm{cm}^{2}$, and $0.48 \mathrm{~mA} / \mathrm{cm}^{2}$ and $-0.06 \mathrm{~mA} / \mathrm{cm}^{2}$, respectively. The Ag/CIS-NRs $/ \mathrm{p}^{+}$-Si device was the better investigated device because its on/off ratio was 2.12, which is larger than those of ITO/CIS-NRs/ $\mathrm{p}^{+}-\mathrm{Si}$ (2.12) and ITO/CIS-TF/Mo/glass (3.98) devices. The measured built voltage $\left(V_{b i}\right)$ of the Ag/CIS-NRs $/ \mathrm{p}^{+}$-Si diode was $0.22 \mathrm{~V}$, and the Schottky barrier $\left(\Phi_{\mathrm{SH}}\right)$ and carrier concentration $\left(N_{A}\right)$ of CIS-NRs were $0.7 \mathrm{~V}$ and $1.38 \times 10^{11} \mathrm{~cm}^{-3}$, respectively.

Author Contributions: Conceptualization, J.L., M.-P.H., and C.-F.Y.; methodology, K.-W.L., M.-P.H., and C.-F.Y.; validation, J.L., K.-W.L., M.-P.H., and C.-F.Y.; formal analysis, J.L., K.-W.L., M.-P.H., and C.-F.Y.; investigation, J.L., K.-W.L., and M.-P.H.; data curation, J.L., K.-W.L., M.-P.H., and C.-F.Y.; writing-original draft preparation, J.L., M.-P.H., and C.-F.Y.; writing - review and editing, J.L., M.-P.H., and C.-F.Y.; visualization, K.-W.L. and M.-P.H.; project administration, J.L., M.-P.H., and C.-F.Y. All authors have read and agreed to the published version of the manuscript.

Funding: This work was supported by projects under Nos. MOST 108-2221-E-390-005, MOST 108-2622-E-390-002-CC3, and MOST-108-2221-E-006-042. This research was also funded by the Key Science and Technology Project of Fujian Province (grant number 2019H0022) and the Foundation for Young Scientists of Jimei University (grant number ZR2019002).

Conflicts of Interest: The authors declare no conflict of interest.

\section{References}

1. Haloui, H.; Touafek, K.; Zaabat, M.; Ben cheikh el hocine, H.; Khelifa, A. The Copper Indium Selenium (CuInSe2) thin films solar cells for Hybrid Photovoltaic Thermal Collectors (PVT). Energy Procedia 2015, 74, 1213-1219. [CrossRef]

2. Friedlmeier, T.M.; Jackson, P.; Bauer, A.; Hariskos, D.; Kiowski, O.; Menner, R.; Wuerz, R.; Powalla, M. High-efficiency $\mathrm{Cu}(\mathrm{In}, \mathrm{Ga}) \mathrm{Se}_{2}$ solar cells. Thin Solid Films 2017, 633, 13-17. [CrossRef]

3. Keller, J.; Schlesiger, R.; Riedel, I.; Parisi, J.; Schmitz, G.; Avellan, A.; Dalibor, T. Grain boundary investigations on sulfurized $\mathrm{Cu}(\mathrm{In}, \mathrm{Ga})(\mathrm{S}, \mathrm{Se})_{2}$ solar cells using atom probe tomography. Solar Energy Mater. Solar Cells 2013, 117, 592-598. [CrossRef]

4. Kim, J.; Lee, H.S.; Park, N.M. Post-annealing effect on the reactively sputter-grown CIGS thin films and its influence to solar cell performance. Curr. Appl. Phys. 2014, 14, S63-S68. [CrossRef]

5. Ouyang, L.Q.; Zhao, M.; Zhuang, D.M.; Han, J.F.; Guo, L.; Li, X.L.; Cao, M.G. The relationships between electronic properties and microstructure of $\mathrm{Cu}(\mathrm{In}, \mathrm{Ga}) \mathrm{Se}_{2}$ films prepared by sputtering from a quaternary target. Mater. Lett. 2014, 137, 249-251. [CrossRef]

6. Ruffenach, S.; Robin, Y.; Moret, M.; Aulombard, R.L.; Briot, O. (112) and (220)/(204)-oriented CuInSe $\mathrm{I}_{2}$ thin films grown by co-evaporation under vacuum. Thin Solid Films 2013, 535, 143-147. [CrossRef]

7. Lindahl, J.; Zimmermann, U.; Szaniawski, P.; Torndahl, T.; Hultqvist, A.; Salome, P.; Bjorkman, C.P.; Edoff, M. Inline $\mathrm{Cu}(\mathrm{In}, \mathrm{Ga}) \mathrm{Se}_{2}$ Co-evaporation for High-Efficiency Solar Cells and Modules. IEEE J. Photovolt. 2013, 3, 1100-1105. [CrossRef]

8. Diao, C.C.; Kuo, H.H.; Tzou, W.C.; Chen, Y.L.; Yang, C.F. Fabrication of CIS Absorber Layers with Different Thicknesses using a Non-Vacuum Spray Coating Method. Materials 2014, 7, 206-217. [CrossRef]

9. Burgos, A.; Schrebler, R.S.; Gomez, H.; Catano, F.A.; Marotti, R.E.; Dalchiele, E.A. Potential Pulsed Electrodeposition of CuInSe 2 Thin Films. Inter. J. Electrochem. Sci. 2015, 10, 10543-10553.

10. Saber, S.; Mollar, M.; Nahrawy, A.E.; Khattab, N.; Eid, A.; Aly, M.A.; Mari, B. Annealing study of electrodeposited CuInSe 2 and $\mathrm{CuInS}_{2}$ thin films. Opt. Quant. Electron. 2018, 50, 248. [CrossRef] 
11. Lin, S.X.; Shi, X.H.; Zhang, X.; Kou, H.H.; Wang, C.M. Ternary semiconductor compounds CuInS 2 (CIS) thin films synthesized by electrochemical atomic layer deposition (EC-ALD). Appl. Sur. Sci. 2012, 256, 4365-4369. [CrossRef]

12. Chang, T.W.; Hu, S.Y.; Lee, W.H. Synthesis of CuInSe $e_{2}$ thin films from electrodeposited $\mathrm{Cu}_{11} \mathrm{In}_{9}$ precursors by two-step annealing. J. Electrochem. Sci. Eng. 2014, 4, 27-35. [CrossRef]

13. Sidali, T.; Bou, A.; Coutancier, D.; Chassaing, E.; Theys, B.; Barakel, D.; Garuz, R.; Thoulon, P.Y.; Lincot, D. Semi-transparent photovoltaic glazing based on electrodeposited CIGS solar cells on patterned molybdenum/glass substrates. EPJ Photovolt. 2018, 9, 2. [CrossRef]

14. Chiang, M.H.; Lin, W.T.; Wang, B.S.; Hsu, K.C.; Fu, Y.S. CuInS 2 nanowires prepared using a hydrothermal process through a polymer-type ion release source. Ceram. Int. 2017, 43, 5819-5822. [CrossRef]

15. Kuo, H.H.; Kuo, C.G.; Yen, C.Y.; Yang, C.F. Using Anodic Aluminum Oxide Templates and Electrochemical Method to Deposit BiSbTe-Based Thermoelectric Nano-Wires. Nanoscale Res. Lett. 2014, 9, 63. [CrossRef]

16. Hamrouni, S.; Boujmil, M.F.; Ben Saad, K. Electrical Properties of the Al/CuInSe 2 Thin Film Schottky Junction. Adv. Mater. Phys. Chem. 2014, 4, 224-235. [CrossRef]

17. Noufi, R.; Axton, C.; Herrington, S.K. Deb, Electronic properties versus composition of thin films of CuInSe 2 . Appl. Phys. Lett. 1984, 45, 668. [CrossRef]

18. Capon, B.R.; Dierick, R.; Hens, Z.; Detavernier, C. Formation of CuInSe $e_{2}$ films from metal sulfide and selenide precursor nanocrystals by gas-phase selenization, an in-situ XRD study. Thin Solid Films 2016, 612, 208-213. [CrossRef]

19. Rincon, C.; Ramlrez, F.J. Lattice vibrations of $\mathrm{CulnSe}_{2}$ and $\mathrm{CuGaSe}_{2}$ by Raman microspectrometry. J. Appl. Phys. 1992, 72, 4321-4324. [CrossRef]

20. Mobarak, M.; Zied, M.A.; Mostafa, M.; Asharia, M. Effects of growth technique on the microstructure of $\mathrm{CuInSe}_{2}$ ternary semiconductor compound. Heliyon 2020, 6, e03196. [CrossRef]

21. Chkoda, L.; Heske, C.; Sokolowski, M.; Umbach, E.; Steuber, F.; Staudigel, J.; Stoßel, M.; Simmerer, J. Work function of ITO substrates and band-offsets at the TPD/ITO interface determined by photoelectron spectroscopy. Synth. Metals 2000, 111-112, 315-319. [CrossRef]

22. Beerbom, M.M.; Lagel, B.; Cascio, A.J.; Doran, B.V.; Schlaf, R. Direct comparison of photoemission spectroscopy and in situ Kelvin probe work function measurements on indium tin oxide films. J. Electron. Spectros. Relat. Phenomena 2006, 152, 12-17. [CrossRef]

23. Guillen, C.; Herrero, J. Structure, morphology and photoelectrochemical activity of CuInSe 2 thin films as determined by the characteristics of evaporated metallic precursors. Sol. Energy Mater. Solar Cells 2002, 73, 141-149. [CrossRef]

24. Tecimer, H.; Aksu, S.; Uslu, H.; Atasoy, Y.; Bacaksız, E.; Altındal, S. Schottky diode properties of CuInSe 2 films prepared by a two-step growth technique. Sens. Actuators A 2012, 185, 73-81. [CrossRef] 